\title{
Computational Simulations of Wind Loads of Super Tall Buildings in Hilly Terrain
}

\author{
Bowei Liu ${ }^{1,2, a}$,Yi Sun ${ }^{1,2}$ and Mei Wang ${ }^{1,2}$ \\ ${ }^{1}$ School of Civil Engineering and architecture, Chongqing University of science and technology. 401331, China \\ ${ }^{2}$ Chongqing Key Laboratory of Energy Engineering Mechanics \& disaster prevention and mitigation, Chongqing, 401331, China
}

\begin{abstract}
The wind loads could be increased by the complex hilly terrain. In order to consider this threat, computational simulations about wind pressures in buildings in hilly terrain and surrounding buildings were finished. In the CFD model, surrounding buildings within 500 meters and hilly terrain within 700 meters were established, and total 16 cases including different sensitive wind directions were simulated. The results showed that, because of the complex situation of surrounding hilly terrain and interfered buildings, wind loads in the building group under different direction show opposite characteristics. The speed-up effects by the hilly terrain increased the windward mean pressures when the flow comes from the north, while the interference effects by the surrounding buildings decreased them when the flow comes from the south.
\end{abstract}

\section{Introduction}

In hilly terrain, wind field near the ground can be changed dramatically by the hills, and be totally different from which in flat regions. Sometimes it can be dangerous to the building safety because wind loads on buildings could be enlarged.

From the 1970s, some scholars began to investigate the speed-up effect in hilly terrain by wind tunnel tests and computational simulations. Jackson and $\mathrm{Hunt}^{[1]}$ promoted an analytical algorithm to compute wind velocity in 2-dimensional smooth hills. Then this algorithm was inspected in wind tunnel test by Jackson ${ }^{[2]}$ and modified by Hunt ${ }^{[3]}$, and became more improved. After that Mason and Sykes ${ }^{[4]}$ extended this algorithm to single 3-dimensional hills, and Kaimal and Finnigan ${ }^{[5]}$ figured out that the error of this algorithm could be less than $15 \%$. Taylor and $\mathrm{Lee}^{[6]}$ provided a simplified method to calculate the changed wind velocity in different height from ground, which is called "the original guidelines". Gong and Ibbetson ${ }^{[7]}$ finished some wind tunnel tests on 2-dimensional and symmetric 3dimensional hill models. Holmes ${ }^{[8]}$ and Glanville ${ }^{[9]}$ utilized the methods of field test and wind tunnel test to investigate the separate effects in a steep hill. Neff ${ }^{10]}$ simulated different density of trees in hills by wind tunnel tests and discussed the influence on wind fields in hills. Miller and Davenport ${ }^{[11]}$ finished wind tunnel tests on continuous 12 2-dimensional hills and discussed the speed-up effects. Taylor ${ }^{[12]}$ and Weng ${ }^{[13]}$ investigated the effects of geometry of hills and ground roughness on speed-up effects by their computational simulation functions of boundary layer, MFSD. In their researches, a new algorithm was promoted, which took the ground roughness into account during calculating the speed-up ratio. This algorithm was called "the new guidelines".

In this paper, the wind loads of a super tall building group in complex hilly terrain and surrounding interfered buildings were discussed by computational simulations in software Fluent. The wind pressures on the surfaces of buildings under 16 sensitive wind directions were discussed.

\section{Characteristics of the building group and hilly terrain}

This building group was located in a central business district, with some other super tall buildings surrounded. In order to consider the interference effects, the computational region were set including the buildings within 500 meters. In the south part, the hill is steep and there was a river 700 meters far away. Because of the influence on wind pressures, the terrain within 700 meters in southern was included. The plane view of buildings and hilly terrain were shown in figure 1 .

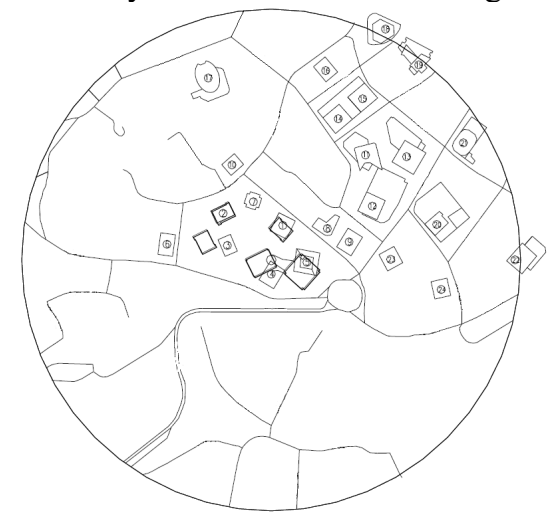

(a) Surrounding buildings 


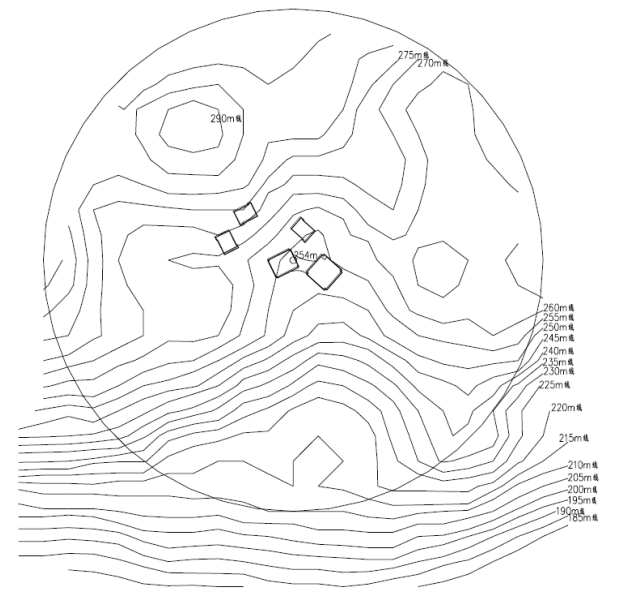

(b) The features of terrain

Figure 1. The buildings and hilly terrain

\section{CFD model}

Simulations in this paper were engaged by the software Fluent, which was widely used in solving fluid problems. Turbulence model of realizable $k-\varepsilon$ was adopt, which is a modification of standard $k-\varepsilon$ model, and was considered an effective model to cope with the problems of flow in boundary layer.

The windward boundary were set to velocity-inlet, in which the wind profile was set in formula (1), the turbulence profile was set in formula (2), and some turbulence parameters ,kinetic energy and dissipation ratio, were set in formula (3) and (4).

$$
\begin{gathered}
V(z)=V_{10}\left(\frac{350}{10}\right)^{0.16}\left(\frac{z}{450}\right)^{0.3} \\
I(z)=0.15(z / H)^{-0.05-\alpha}=0.15(z / H)^{-0.05-0.3}
\end{gathered}
$$

$$
\begin{gathered}
k=\frac{3}{2}\left(u I_{z}\right)^{2} \\
\varepsilon=C_{\mu}^{3 / 4} \frac{k^{3 / 2}}{l}
\end{gathered}
$$

In these formula, $C_{\mu}=0.09$. Parameter $l$ is turbulence integral scale, and $l=0.07 L$, in which $\mathrm{L}$ are the typical geometry of buildings. The wind velocity profile, turbulence kinetic energy and dissipation rate were set by user-defined functions in Fluent.

The top and lateral boundaries were set to symmetry, and the leeward boundary was set to pressure-outlet. The faces of building and ground were set to wall, which were modified by roughness surface.

The grids of CFD models were shown in figure 2.

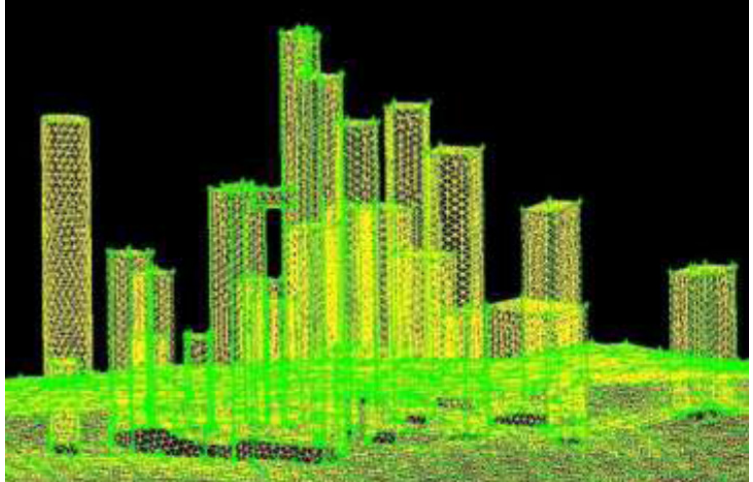

Figure 2. The grids of CFD models

In the simulations, cases of wind from 16 direction were simulated by rotating the building and terrain model. However, the 16 directions were not divided from 360 degree uniformly. Instead, these directions included 4 normal direction( $0,90,180,270), 4$ directions perpendicular to surface of building R5(26, 206, 116, 296), 4 directions perpendicular to surface of building R6(48, 228, 138, 318), and 4 directions parallel and perpendicular to the connection between R5 and R6(159, $339,249,69)$. The 16 directions were shown in figure 3 .

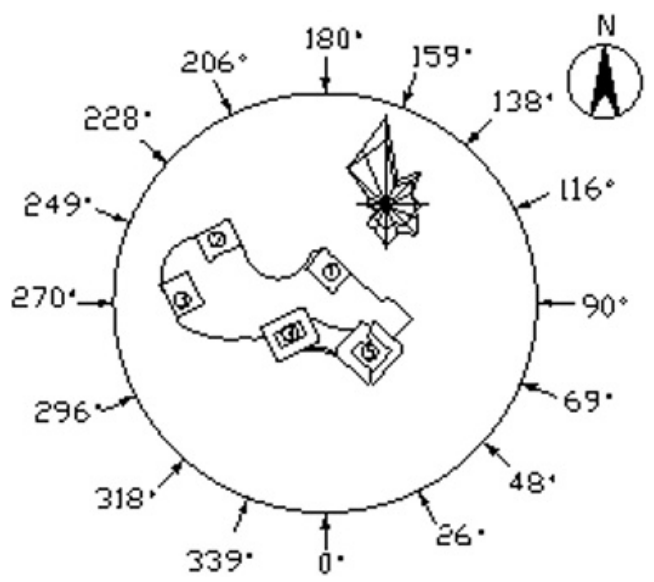

Figure 3. Cases of wind directions in simulations

\section{Wind pressures in the surfaces of buildings}

The contours of wind pressures in the surfaces of buildings were shown in figure 4 .

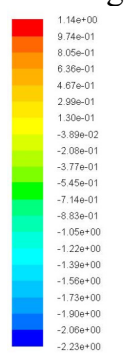

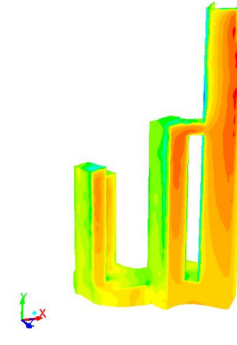

(a)Direction 0

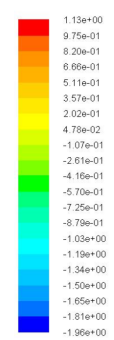

x.

(b) Direction 26 

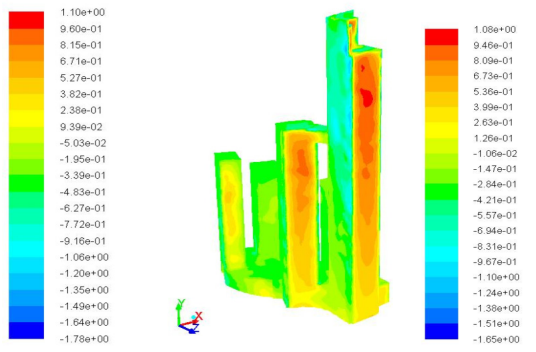

(c) Direction 48
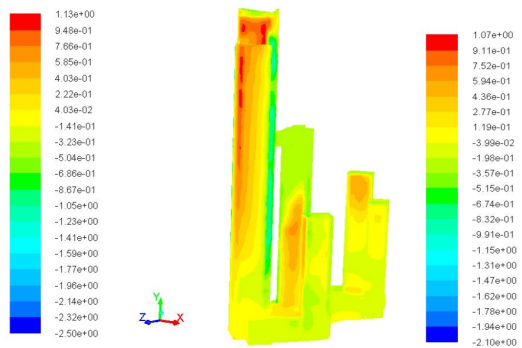

(e) Direction 90
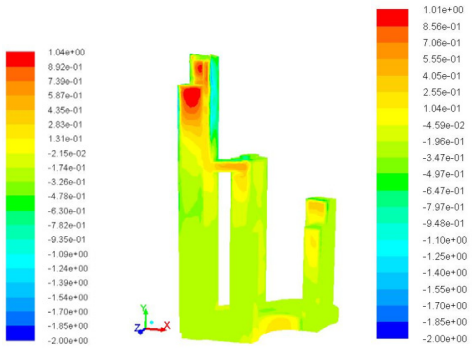

(g) Direction 138
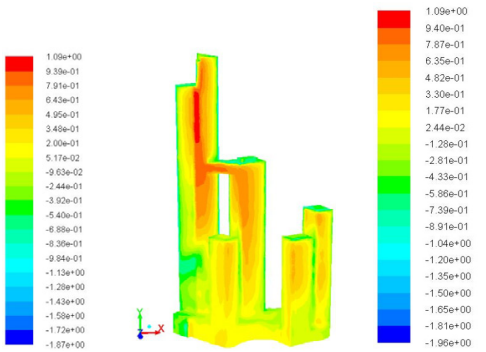

(i) Direction 180
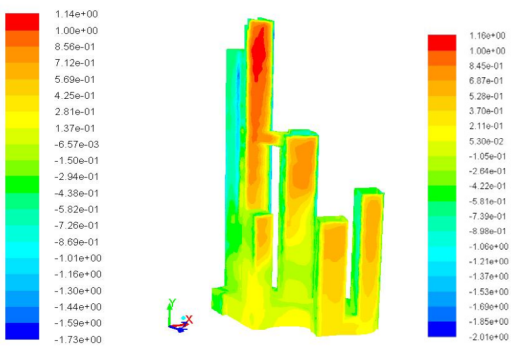

(k) Direction 228 (d) Direction 69

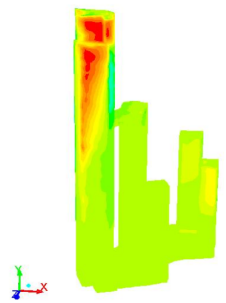

(f) Direction 116
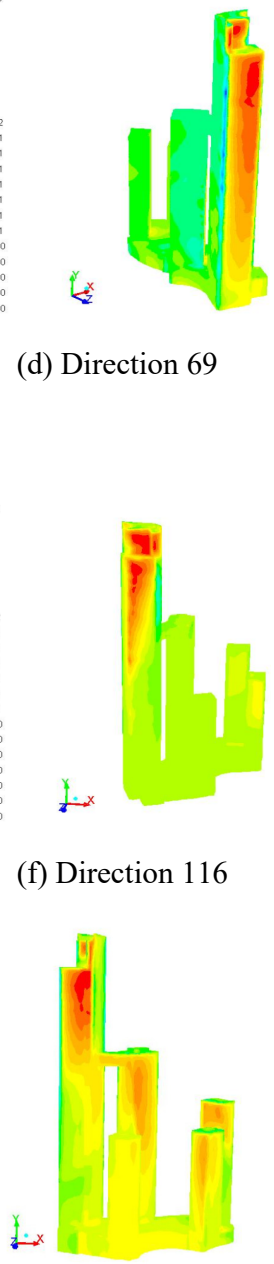

(h) Direction 159

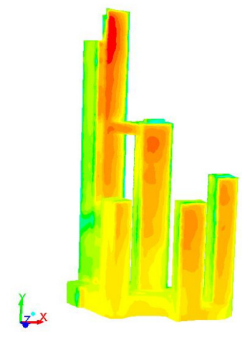

(j) Direction 206

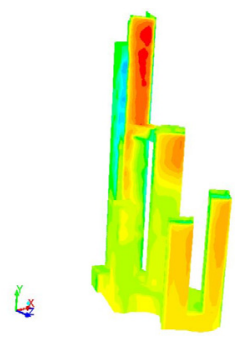

(1) Direction 249
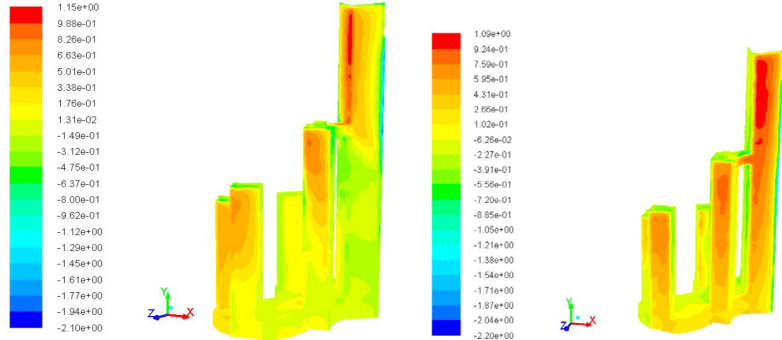

(m) Direction 270

(n) Direction 296
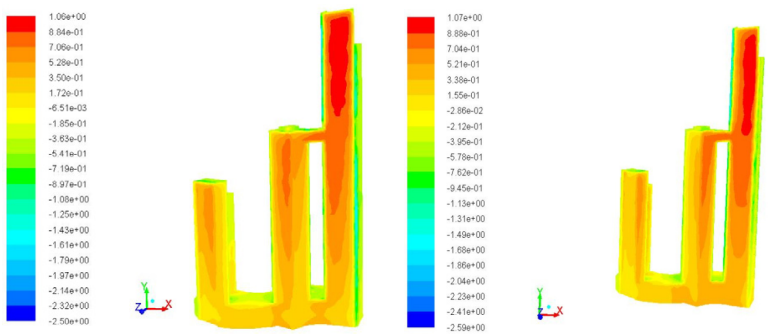

(o) Direction 318

(p) Direction 339

Figure 4. The wind pressure contours.

According to the contours of wind pressures in the buildings, some phenomena caused by hilly terrain could be observed.

Firstly, the maximum positive pressure emerged in the upper part of building R6, and the pressure coefficients were larger than 1 . This was the obvious effect of speed-up by hills. In the maximum part, the wind loads was increased by $10 \%$.

From different direction, wind would cause different effects. Coming from the $\operatorname{south}(339,0,26)$, the windward pressures were increased by the terrain. Coming from the north $(159,180,206)$, the windward pressures were interfered by surrounding buildings, and the windward pressures were decreased notably.

\section{Conclusions}

In this paper, computational simulations on wind pressures of super tall buildings in hilly terrains were investigated. In order to consider the effects, surrounding building were included in the CFD models. According to the results, some conclusions could be got as following.

(1) When the cases of wind direction are considered, the most sensitive directions should be taken into account, rather than dividing the whole 360 degrees uniformly.

(2) During the simulations, the speed-up effects increased the windward mean pressures while the interference effects decreased them.

\section{Acknowledgements}

This research is funded by Chongqing Research Program of Basic Research and Frontier Technology (No. cstc2015jcyjA30016), Research Foundation of 
Chongqing University of Science \& Technology (No. CK2015B15, No. CK2016Z17).

\section{References}

1. P. S. Jackson, J. C. R. Hunt. Turbulent wind flow over a low hill[J]. Quarterly Journal of the Royal Meteorological Society 101, 929-955 (1975)

2. P. S. Jackson. The influence of local terrain features on the site selection for wind energy generating systems[M]. Boundary Layer Wind Tunnel Laboratory, Faculty of Engineering Science, University of Western Ontario. (1979)

3. J. C. R. Hunt. Turbulent shear flows over low hills[J]. Quarterly Journal of the Royal Meteorological Society, 114, 1435-1470 (1988)

4. P. J. Mason, R. I. Sykes. Flow over an isolated hill of moderate slope, Quart[J]. Quarterly Journal of the Royal Meteorological Society 105, 383-395 (1979)

5. J. C. Kaimal, J. J. Finnigan. Atmospheric boundary layer flows: Their structure and measurement[M]. New York: Oxford Univercity Press (1994)

6. P. A. Taylor, R. J. Lee. Simple guidelines for estimating wind speed variations due to small scale topographic features[J]. Climatol. Bull, 18(2), 3-22 (1984)

7. W. Gong, A. Ibbetson. A wind tunnel study of turbulent flow over model hills[J]. Boundary-Layer Meteorology, 49(1), 113-148 (1989)

8. J. D. Holmes, R. W. Banks, P. Paevere. Measurements of topographic multipliers and flow separation from a steep escarpment. Part I. Full scale measurements[J]. Journal of Wind Engineering and Industrial Aerodynamics, 69, 885-892 (1997)

9. M. J. Glanville, K. C. S. Kwok. Measurements of topographic multipliers and flow separation from a steep escarpment. Part II. Model-scale measurements[J]. Journal of Wind Engineering and Industrial Aerodynamics, 69, 893-902 (1997)

10. D. E. Neff, R. N. Meroney. Wind-tunnel modeling of hill and vegetation influence on wind power availability $[\mathrm{J}]$. Journal of Wind Engineering and Industrial Aerodynamics, 74, 335-343 (1998)

11. C. A. Miller, A. G. Davenport. Guidelines for the calculation of wind speed-ups in complex terrain[J]. Journal of Wind Engineering and Industrial Aerodynamics, 74, 189-197 (1998)

12. P. A. Taylor. Turbulent boundary-layer flow over low and moderate slope hills $[\mathrm{J}]$. Journal of Wind Engineering and Industrial Aerodynamics, 74, 25-47 (1998)

13. W. Weng, P. A. Taylor, J. L. Walmsley. Guidelines for airflow over complex terrain: model developments[J]. Journal of Wind Engineering and Industrial Aerodynamics, 86(2-3), 169-186 (2000) 